\title{
Educação, currículo e diferenças: uma análise dos povos indígenas na educação escolar do Mato Grosso do Sul, Brasil
}

[ Education, curriculum and differences: an analysis of indigenous people into the school education from Mato Grosso do Sul state, Brazil

\section{Sanderson Pereira Leal ${ }^{\mathrm{I}}$ \\ Walter Guedes da Silva ${ }^{2}$}

RESUMO - Este artigo é fundamentado em pesquisa realizada sobre o currículo da educação escolar do estado de Mato Grosso do $\mathrm{Sul}$ (MS) e tem como objetivo analisar como os conteúdos relacionados às culturas e histórias dos povos indígenas, instituídos pela Lei $\mathrm{n}$. II.645/08, são apresentados no Referencial Curricular para o Ensino Médio (RCEM) na área de ciências humanas. Com a implantação da Lei de Diretrizes e Bases da Educação Nacional (LDB) e a criação da Lei n. II.645, de 2008, novos desafios surgiram aos profissionais $\mathrm{da}$ educação básica. O não cumprimento dessas leis pode prejudicar a construção de uma postura crítica dos professores e estudantes sobre os conhecimentos que tratam dos povos indígenas que lutam pela sobrevivência de suas histórias, culturas e direitos diante do histórico contato interétnico de preconceito e de violência por parte dos não indígenas. PALAVRAS-CHAVE • Educação básica; currículo; cultura; indígenas.

\begin{abstract}
- ABSTRACT - This paper work is based on a research carried out about the school education curriculum from Mato Grosso do Sul State and it has as aim to analyze how the contents related to cultures and histories of indigenous peoples, instituted by Law $n^{\circ}$ II.645/2008, are presented inside the Curriculum Referential for the High School in the human sciences area. With the implementation of the Law of Directives and Basis for National Education and the creation of the Law $n^{\circ}$ II.645/2008 new challenges have emerged for basic education professionals. The failure to comply with these laws may hinder the construction of a critical attitude of teachers and students about the knowledge that they deal with indigenous people who struggle for the survival of their histories, cultures and rights beyond the historical interethnic contact of prejudice and violence by the non-indigenous people. . KEYWORDS - Basic education; curriculum; culture; indigenous.
\end{abstract}

Recebido em 5 de setembro de 2019

Aprovado em 28 de setembro de 2020

LEAL, Sanderson Pereira; SILVA, Walter Guedes da. Educação, currículo e diferenças: uma análise dos povos indígenas na educação escolar do Mato Grosso do Sul, Brasil. Revista do Instituto de Estudos Brasileiros, Brasil, n. 77, p. 5I-69, dez. 2020.

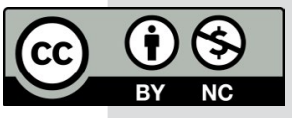

DOI: https://doi.org/Io.II6o6/issn.23I6-90IX.vIi77p5I-69

I Secretaria Estadual de Educação de Mato Grosso do Sul (SED, Campo Grande, MS, Brasil).

2 Universidade Estadual de Mato Grosso do Sul (UEMS, Campo Grande, MS, Brasil). 
Ao propormos estudos sobre as culturas e histórias indígenas na educação pública no estado do Mato Grosso do Sul (MS), mais especificamente no currículo do ensino básico3, expomos o pensamento de que os povos indígenas em território sul-mato-grossense demandam uma preocupação maior do estado brasileiro e da sociedade civil organizada devido à quantidade de indígenas presentes nesse estado - que possui a segunda maior população indígena do Brasil (IBGE, 20Io) - e, principalmente, ao crescimento de diversas formas de violência cometidas contra esses povos dentro e fora do ambiente sociocultural a que pertencem.

Segundo dados informados pela Secretaria Especial de Saúde Indígena (Sesai) coletados pelo Conselho Indigenista Missionário (CIMI, 20I7, p. 86), no período de 2003 a 2017 o estado do Mato Grosso do Sul contabilizou 46I assassinatos de indígenas de I.II9 ocorridos em todo o território brasileiro, o que corresponde a $4 \mathrm{I} \%$ do total de assassinatos de indígenas no período.

As principais causas dessa violência estão relacionadas aos conflitos com produtores rurais pelo uso e/ou posse de terras e ao confinamento dos povos indígenas em reservas que não permitem a sobrevivência integral desses povos, contribuindo com a criminalidade ligada ao uso de entorpecentes em espaços com pouco ou quase nenhum investimento por parte dos órgãos oficiais de segurança e de saúde. Destacamos também a falta de oportunidades e o preconceito nos centros urbanos, para onde muitos indígenas migram em busca de sustento ou porque foram expulsos de suas terras de origem pela ameaça e violência de grupos hegemônicos que têm interesses contrários à autonomia política de etnias indígenas no estado (CIMI, 20I7).

$\mathrm{O}$ controle e o confinamento de muitas comunidades indígenas em reservas indígenas ao longo do século XX e os conflitos adjacentes às questões sociais, associados à omissão do poder público, são fatores importantes para entender as mortes violentas dentro das aldeias no Mato Grosso do Sul, principalmente entre as etnias guarani e kaiowá concentradas no sul do estado. Segundo Brand (I998,

3 A educação básica brasileira é estruturada em educação infantil, de o a 5 anos de idade; ensino fundamental, de 6 a I4 anos de idade; e ensino médio, que possui três anos de duração. 
p. 39), “a data da destruição das aldeias está relacionada diretamente ao avanço do desmatamento e corresponde à implantação das fazendas”.

Wenceslau e Silva alertam que o processo de expropriação de terras indígenas não é algo característico apenas do estado do Mato Grosso do Sul:

A organização político-administrativa autoritária sobre os indígenas, principalmente a partir da criação do Serviço de Proteção aos Índios - SPI e depois com a Fundação Nacional do Índio - FUNAI, impôs o confinamento dos kayowá e todos os indígenas no Brasil, que passaram a viver em pequenas áreas, sem levar em consideração a essência das diferenças de cada povo e cada comunidade. Esse fato interferiu diretamente na organização das famílias extensas ou nucleares, ou seja, muitas aldeias foram transformadas em um único espaço. (WENCESLAU; SILVA, 20II, p. 4-5).

As determinantes econômicas que envolveram políticas nacionais de expropriação de terras indígenas para o cultivo de atividades ligadas ao agronegócio possibilitam compreender o processo discriminatório imposto às comunidades indígenas dentro do Mato Grosso do Sul, o que se reflete, diretamente, nos processos educacionais das escolas do estado.

As bases da construção de conhecimentos com os estudantes sobre a temática indígena se relacionam com o senso comum, determinado, em grande parte, pelos meios de comunicação de massa, que, na maioria das vezes, são destituídos de postura crítica e imparcial, demonstrando submissão política aos interesses fundiários dentro do estado.

Isso também pode ocorrer nas escolas; materiais didáticos de apoio ao processo ensino-aprendizagem também podem contribuir com o aumento dos preconceitos sobre os saberes e a realidade sociocultural dos povos indígenas. A respeito das culturas indígenas, Leal e Calderoni (2015, p. 476) destacam que,

Partindo de uma premissa sobre um possível silenciamento em relação aos povos indígenas dentro de um artefato cultural de extrema importância para o trabalho docente e para a construção das identidades indígenas, como é o caso do livro didático, torna-se praticamente difícil a inserção de temas relacionados à diversidade cultural na sociedade nacional e, portanto, [o que] tende a fortalecer estereótipos e representações generalizantes e imprecisas sobre estes povos que há séculos são aceitas e mantidas como verdadeiras pela visão etnocêntrica dominante.

Diante de uma educação pública mantenedora de certas posições de exclusão das diferenças em seu currículo e nos livros didáticos, que interferem nos diálogos e na construção do conhecimento nas salas de aula, ao professor é reservado um papel primordial a favor dos grupos indígenas, desconstruindo discursos dominantes de base etnocêntrica que dificultam o estudo e a compreensão desses povos na sociedade e suas instituições.

O professor, agente principal de socialização no espaço escolar, é chamado à responsabilidade de educar de acordo com preceitos constitucionais de valorização da cidadania e consolidação da democracia. Segundo o artigo 23I da Constituição 
Federal, "São reconhecidos aos índios sua organização social, costumes, línguas, crenças e tradições, e os direitos originários sobre as terras que tradicionalmente ocupam, competindo à União demarcá-las, proteger e fazer respeitar todos os seus bens" (BRASIL, 20I6).

Para que haja aprendizado sobre os povos indígenas no âmbito do ensino médio das escolas estaduais, que não se reduza a uma ínfima presença da temática dentro do currículo, os professores das diversas áreas do saber necessitam de conhecimentos e informações sobre as diversas culturas, realidades e saberes desses povos presentes em todo o território nacional. Esses conhecimentos são importantes para os profissionais da educação básica comprometidos com uma visão crítica acerca dos problemas sociais enfrentados pelos grupos indígenas ao longo da história de formação do Estado brasileiro.

Nesse sentido, este trabalho busca responder à seguinte questão: como a Lei n. II.645/08 (BRASIL, 2008), que inclui no currículo oficial da rede de ensino a obrigatoriedade da temática história e cultura afro-brasileira e indígena, pode contribuir para que haja respeito aos códigos culturais, aos saberes e aos conhecimentos dos povos indígenas?

Nessa perspectiva, o objetivo deste artigo é analisar como os conteúdos relacionados às culturas e histórias dos povos indígenas, instituídos pela Lei n. II.645/08, são apresentados no Referencial Curricular para o Ensino Médio do Mato Grosso do Sul (RCEM/MS) das áreas de ciência humanas - história, geografia, sociologia e filosofia.

Enquanto embasamento teórico-metodológico, este trabalho se fundamenta nos estudos relacionados à cultura e à identidade como formas de compreensão das relações de poder e das diferenças constituidoras da sociedade. Por meio da corrente pós-colonial, pretendemos analisar conteúdos que expressam os interesses de grupos sociais históricos que estabeleceram políticas públicas excludentes.

As pesquisas relacionadas aos chamados estudos culturais têm se constituído como um campo teórico importante dentro das ciências sociais, principalmente a partir da segunda metade do século XX. A respeito dos estudos culturais, Urquiza e Calderoni (20I5, p. I4) afirmam que o "foco analítico de suas produções é gerado em torno de três conceitos básicos: cultura, poder e identidade. Entretanto, o termo 'cultura' é uma categoria-chave e um ponto de partida".

As diferenças não podem ser entendidas dentro de um esforço social por admitir e/ou admirar a diversidade étnica ou cultural em seu "exotismo" historicamente imposto pela ideologia hegemônica eurocêntrica. As diferenças trazem consigo as contradições, as lutas, as relações conflituosas, a dialética dos grupos e do confronto real das relações de alteridade dentro de espaços “híbridos" essenciais à construção da identidade coletiva de um povo e/ou etnia, relações híbridas estudadas e analisadas por Bhabha (2005).

A educação básica, em seu conjunto ideológico e representativo do pensamento hegemônico eurocêntrico, mais especificamente a sua estrutura curricular, é analisada por meio de um processo de descolonização, ou seja, de desconstrução e/ ou desnaturalização de estereótipos arraigados no pensamento coletivo e, também, de confronto com os estigmas criados que silenciam as diferenças indígenas dentro dos conteúdos legitimadores de uma verdade única. 
A Lei n. II.645/08 é um dos pilares de análise metodológica deste trabalho, pois está na base da construção das análises realizadas sobre a não presença da temática indígena no currículo do ensino médio no Mato Grosso do Sul. É a partir da referida lei que o Referencial Curricular e os livros didáticos são analisados neste trabalho como instrumentos e mecanismos políticos ideológicos. Sua análise está diretamente articulada aos trabalhos que tratam de seu não cumprimento e da marginalização da temática indígena na educação básica, retratados por Silva (20I0), Graúna (20II) e Bittencourt (2013).

As determinações que norteiam o currículo do ensino médio na educação brasileira foram estabelecidas com base nas Diretrizes Curriculares Nacionais para o Ensino Médio - DCNEMs (BRASIL, 20I3) e nos Parâmetros Curriculares Nacionais para o Ensino Médio - PCNEMs (BRASIL, 2006). Dessa perspectiva, as leituras de Gomes (20I2), Gilaverte (20I4), Vasconcelos (2004), Arroyo (2013) e Moreira (200I) tornaram-se importantes para as análises que buscaram compreender as ideologias e disputas em jogo no RCEM/MS, que indicam uma clara omissão do documento em relação à temática indígena, identificando a naturalização e a legitimação de conteúdos que tendem a traduzir os interesses de grupos econômica e historicamente hegemônicos na sociedade brasileira.

Também foram analisados os livros didáticos da área de ciências humanas do ensino médio do estado (história, geografia, sociologia e filosofia), na perspectiva pós-colonialista, identificando os "erros e esquecimentos" presentes nesses livros.

Além da introdução, o artigo está subdividido em quatro partes. Na primeira, apresentamos as leis de valorização dos povos indígenas na educação básica; a segunda discute a temática indígena no Referencial Curricular do Ensino Médio do Mato Grosso do Sul, com análise nos livros didáticos de história, geografia, sociologia e filosofia; já a terceira parte apresenta propostas e experiências que valorizam os povos indígenas na produção do conhecimento escolar; por fim, na quarta parte apresentamos as considerações finais.

\section{AS LEIS DE VALORIZAÇão doS POVOS INDíGENAS NA EDUCAÇão báSICA}

A própria Lei de Diretrizes e Bases da Educação Nacional (LDB), n. 9394/96 (BRASIL, I996), foi constituída a partir de um projeto político estruturado em uma constituição democrática que estabelece a igualdade de direitos e as liberdades individuais para todos os cidadãos, estabelecendo no inciso I do art. 208 que é dever do Estado garantir a gratuidade da educação básica dos 4 aos I7 anos de idade a todos os brasileiros.

Apesar do recorte histórico deste estudo estar relacionado ao período pós-implantação da LDB, cabe destacar o discurso de intelectuais defensores da educação pública no Brasil da década de I930, que deu sustentação ao Manifesto dos Pioneiros da Educação Nova em I932. Segundo o manifesto, o ensino médio, caracterizado na época como ensino secundário, constituía-se como ponto "nevrálgico" da educação escolar.

Os debates que se iniciaram com o manifesto procuraram designar ao ensino médio funções e responsabilidades que atendem aos anseios dos jovens adolescentes 
e de suas famílias diante da imposição das novas transformações sociais que são impulsionadas pelo advento de um capitalismo altamente tecnológico e excludente. Para tanto é fundamental que ocorra mudança nas ações da escola e dos professores para pensar esses jovens, como apontam Carmo e Eddine (2013, p. 235): "Ser humano é se tornar humano, é ser diferente, e é essa diferença que nos faz indivíduos únicos. Rever ações é sempre a forma de respeitar o outro e o modo de se relacionar com o outro".

Nesse sentido, a LDB se constituiu num instrumento legal de regulamentação da educação básica a partir dos princípios da Constituição de I988 e, para tanto, buscou estruturar o ensino médio na proposta de universalização da educação básica. $\mathrm{O}$ ensino médio "assim entendido, tornou-se constitucionalmente gratuito e também, por lei ordinária, progressivamente obrigatório” (CURY, 2002, p. I8I-I82).

A LDB apresenta a seguinte referência às diferenças étnicas que contribuíram para a formação da nação: "\$ $4^{\circ} \mathrm{O}$ ensino da História do Brasil levará em conta as contribuições das diferentes culturas e etnias para a formação do povo brasileiro, especialmente das matrizes indígena, africana e europeia” (LDB, 20I7, p. 20).

Em uma análise sobre a presença dos povos indígenas nos PCNEMs e DCNEMs, especificamente na área de ciências humanas, foi possível perceber a necessidade de considerar as diferenças étnicas que contribuíram para a construção da identidade nacional dentro de um processo de desconstrução/desnaturalização de preconceitos e do reconhecimento do "outro" em suas particularidades e anseios por autonomia política.

Outra grande mudança importante dentro da LBD para a inclusão da temática indígena - culturas e histórias - na educação básica foi a promulgação da Lei n. II.645, de 2008, que estabeleceu, no art. 26-A da LDB, o seguinte ordenamento:

Nos estabelecimentos de ensino fundamental e de ensino médio, públicos e privados, torna-se obrigatório o estudo da história e cultura afro-brasileira e indígena.

$\S$ I . O conteúdo programático a que se refere este artigo incluirá diversos aspectos da história e da cultura que caracterizam a formação da população brasileira, a partir desses dois grupos étnicos, tais como o estudo da história da África e dos africanos, a luta dos negros e dos povos indígenas no Brasil, a cultura negra e indígena brasileira e o negro e o índio na formação da sociedade nacional, resgatando as suas contribuições nas áreas social, econômica e política, pertinentes à história do Brasil.

$\S 2^{\circ}$. Os conteúdos referentes à história e cultura afro-brasileira e dos povos indígenas brasileiros serão ministrados no âmbito de todo o currículo escolar, em especial nas áreas de educação artística e de literatura e história brasileiras. (LDB, 20I7, p. 2I).

As demandas pela inclusão da temática indígena e afro-brasileira e o reconhecimento das diferenças étnico-raciais dentro do currículo da educação básica são resultado das lutas sociais e políticas dos grupos ligados aos movimentos indígenas e negros que historicamente sofreram com a marginalização e o preconceito com relação a suas culturas e identidades. Sobre a implementação da Lei n. II.645/O8, Souza (2013, p. 307) declara que "parece ter o intuito de preencher as páginas em branco da história do Brasil, em que deveria estar registrada a 
participação dos atores indígenas, presentes aos milhares na imensa arena da 'nova terra' então pisada por portugueses”.

Diante do dispositivo da Lei n. II.645/08, os povos indígenas são representados dentro do currículo da educação básica do Brasil com um olhar capaz de desconstruir conteúdos eurocêntricos que mascaravam as diferenças étnicas. No entanto, o que ocorreu não foi exatamente como o previsto na lei, pois, após anos da sua promulgação ainda existe muita resistência em diversos setores da educação básica pela consolidação dos saberes dos povos indígenas. De acordo com Souza (20I3, p. 3I7),

A Lei II.645/2008 deveria ter provocado um grande ciclo de discussões em nível nacional sobre a questão das relações entre diferentes culturas, principalmente no tocante às sociedades indígenas envolventes, o que na verdade não aconteceu. Houve pouca mobilização, alguns pequenos grupos de estudos foram formados, mas não uma mobilização pedagógica mais ampla, com participação de gestores escolares e professores, como era de esperar.

A distância da letra da lei em relação à prática de valorização dos povos indígenas no currículo da educação básica evidencia, segundo Gutierrez (2013), uma sociedade pouco atenta aos interesses e anseios das minorias. O pensamento colonial, ainda dominante nas estruturas institucionais do Brasil, reforça a marginalização de outras culturas e histórias que podem contradizer o discurso dominante. A própria Lei n. II.645/08 carrega conceitos e visões já ultrapassados sobre o modo de pensar e conhecer as minorias indígenas em território brasileiro, conforme abordado por Silva (20I3, p. II6):

No $\$ \mathrm{I}^{\circ}$ encontramos expressões que estão ultrapassadas nas discussões atuais e podem trazer interpretações superficiais, panfletárias: "a luta dos negros e dos povos indígenas", "resgatando", "contribuições nas áreas sociais", "formação da sociedade nacional”. Essas afirmações dão margem a interpretações deturpadas. A expressão "luta dos negros e dos povos indígenas" pode dar lugar a uma abordagem na qual esses povos foram e continuam sendo pensados apenas como vítimas permanentemente em lutas.

A autora problematiza os diferentes aspectos do processo histórico de contatos vividos entre as sociedades indígenas e não indígenas, apontando interpretações equivocadas da lei, destacando que:

A afirmação "formação da sociedade nacional" reforça a ideia corrente de incorporação dos valores socioculturais desses indivíduos no contexto nacional remetendo-nos à "teoria da mestiçagem", na qual os negros e os índios são vistos como um dos elementos apenas formadores na composição da sociedade brasileira. E, quando é de interesse dos administradores dessa sociedade, esses elementos aparecem ou desaparecem oportunamente da cena nacional. (SILVA, 20I3, p. II7). 
Não basta inserir conteúdos que simbolizam uma presença marginalizada dos grupos étnicos indígenas dentro do currículo da educação básica para atender aos dispositivos da Lei n. II.645/08. A escola se distancia de uma verdadeira mudança nas formas de compreender e valorizar conhecimentos e/ou conteúdos sobre os povos indígenas e o desenvolvimento de uma educação intercultural. Mesmo considerando a preocupação dos Parâmetros Curriculares Nacionais (PCNs) sobre a temática indígena nas salas de aula, Souza (2013) afirma que muitas escolas não seguem as orientações desses parâmetros ou a fazem de forma folclorizada.

As diferenças étnicas e o estudo da temática indígena na educação podem não traduzir possibilidades de diálogo e interação com o outro, pois o diferente se distancia do padrão etnocêntrico/normativo no qual as pessoas estão acostumadas a crer. Urquiza e Calderoni (20I5, p. I9) demonstram preocupação em pensar o diferente na sociedade brasileira, pois o reconhecimento de nossas diferenças "não provocou um deslocamento na hierarquização entre os povos que compõem nossa nação, pois essa diferença (étnica) vem carregada de estereótipos e representações que subjugam e subalternizam os povos indígenas”.

De acordo com as DCNEMs, a educação escolar deve permitir o acesso à pluralidade de culturas e buscar desenvolver cidadãos conscientes de seus direitos e deveres na sociedade democrática. A escola é a porta de entrada para o desenvolvimento de uma sociedade justa e igualitária, não só pelo discurso da lei, que é rica e valorativa dos direitos humanos e do respeito à diversidade, mas porque deve oportunizar amplo diálogo entre as diferentes etnias nas práxis diárias de suas ações educativas. Pensar uma escola democrática e comprometida com os direitos e deveres dos jovens cidadãos é também discutir os paradigmas que impedem o acesso aos conhecimentos e saberes das culturas indígenas no país.

\section{A TEMÁTICA INDÍGENA NO REFERENCIAL CURRICULAR DO ENSINO MÉDIO DO MATO GROSSO DO SUl - HISTÓRIA, GEOGRAFIA, SOCIOLOGIA E FILOSOFIA}

O currículo e os livros didáticos são utilizados como referência para o trabalho didático dos professores em sala de aula; a invisibilidade da temática indígena no processo de ensino-aprendizagem corrobora o desrespeito à Lei n. II.645/08 no ensino médio do Mato Grosso do Sul, dificultando a busca por uma educação verdadeiramente inclusiva e democrática.

De acordo com o documento do RCEM/MS, que orienta sobre conteúdos, competências e habilidades que devem ser trabalhados nas diferentes ciências dos conhecimentos, é necessário respeitar e cumprir a Lei n. II.645/08 ao fazer referência direta à valorização dos grupos indígenas no currículo do ensino médio. Porém, no restante do documento introdutório do RCEM/MS, que contém aproximadamente 40 páginas, os povos indígenas aparecem apenas citados indiretamente, poucas vezes e de forma generalizante, como pelo uso de expressões "respeito à diversidade étnico-racial" e "diferenças e singularidades".

A despreocupação com o estudo da temática indígena no currículo nacional conduz a políticas educacionais tradicionais e ainda destoantes da Lei n. II.645/08. Os 
sujeitos colocados à margem pela historiografia e pela elite dominante são silenciados dentro das instituições responsáveis por reproduzirem a lógica cientificista, as "ausências dos sujeitos populares não se dão por ingênuo esquecimento, mas têm uma intencionalidade política, fazem parte dos processos políticos de segregação desses coletivos nos diversos territórios sociais, econômicos, políticos e culturais" (ARROYO, 20I3, p. I43).

O conhecimento escolar reproduz sistemas complexos de dominação que envolvem a submissão de sujeitos, até mesmo em discursos abertos à diversidade e tolerância. Vejamos como a temática indígena é apresentada no livro didático no RCEM/MS nas disciplinas de história, geografia, sociologia e filosofia.

Na disciplina de história, a temática indígena é praticamente ausente nos conteúdos, competências e habilidades a ser ministrados durante os três anos de ensino médio, pois nenhum dos 63 temas que envolvem conhecimentos variados para esses três anos faz menção a conteúdos que contemplem a temática indígena no Brasil. Dos 67 subtemas dessa disciplina, em três há menção à temática indígena duas no primeiro ano e uma no terceiro ano. A primeira expressão aparece de forma generalizada no terceiro bimestre do primeiro ano intitulada "índios brasileiros" dentro do tema "Povos pré-colombianos".

É evidenciada no RCEM/MS uma posição de submissão dos povos indígenas em território brasileiro, pois são representados por meio de uma visão conceitual chamada de pré-colombiana, demarcando o tempo histórico em antes e depois das invasões europeias, ou da chegada de Colombo e começo da colonização do continente americano no fim do século XV. O prefixo "pré" - indutivo dos povos indígenas remete a uma posição de anterioridade, daquilo que ainda não se constitui como algo por completo e acabado, o que não pode ser aceitável e verdadeiro.

O adjetivo "colombiano", depois do prefixo "pré", passa a representar a nova sociedade e/ou cultura já acabada, completa, verdadeira e, portanto, modelo e fim para aqueles que não se constituem em identidades e/ou adjetivos merecedores de uma definição clara, apenas pré.

A generalização e a ausência de definições de identidades étnicas presentes no conceito "índios brasileiros" confundem estudos sobre as diferenças indígenas em território nacional. Os "índios" são uma mesma cultura ou sociedade? Como os "índios" se constituem brasileiros? Existia a nação brasileira ou Estado brasileiro antes da colonização iniciada em I500?

Os povos indígenas em território brasileiro, que somam 305 etnias segundo a Fundação Nacional do Índio - Funai (20I9), possuíam, no período da chegada do colonizador europeu, suas línguas, costumes, religiosidades, cosmologias e especificidades que não se coadunavam com os interesses políticos dos invasores ocidentais.

Na descrição de competências e habilidades do RCEM/MS é possível ver uma contradição em relação aos conteúdos, pois, enquanto aquelas afirmam que o aluno deve ter competência e habilidades para "perceber e respeitar as diversidades étnicas, religiosas, de gerações de classes como manifestações culturais por vezes conflitantes" (MATO GROSSO DO SUL, 20I2, p. 230), os elementos capazes de proporcionar essa percepção e respeito não são expressos em conteúdos conforme já apresentado; ao contrário, a única referência de conteúdo intitulado "índios brasileiros" demonstra 
um reducionismo político em torno de uma identidade-padrão e é forjada segundo os interesses do Estado brasileiro e dos grupos que o controlavam em diferentes épocas.

A segunda descrição da temática indígena no RCEM/MS aparece dentro do tema "Conquistas e colonização na América", com o subtema "Integração e exclusão dos povos indígenas”, no quarto bimestre do primeiro ano.

Esse conteúdo infunde uma perspectiva dualista no processo relacional entre o colonizador europeu e os povos indígenas, havendo, de acordo com o RCEM/ MS, apenas duas opções para os povos indígenas: integração ou exclusão. O extermínio de culturas e povos indígenas inteiros pelo colonizador europeu não aparece como uma perspectiva a analisar, tampouco os processos de interação, que são distintos da integração.

Essa dita integração dos indígenas jamais existiu, pois esses grupos lutaram para manter suas culturas e identidades, enfrentando os interesses políticos dominantes em diversas situações que demandavam falsas integrações. O próprio conceito de "exclusão", emitido pelo Referencial, denota uma superioridade étnica e/ou cultural, pois quem exclui o outro passa a ser portador de legitimidade e poder para determinar os que serão incluídos.

Muitos povos indígenas buscaram o isolamento e a distância dos grupos colonizadores como forma de sobrevivência de suas identidades e não porque foram "excluídos" de uma sociedade que lhes era estranha e nociva. Portanto, no item "Competências e habilidades" do RCEM/MS, que propõe "analisar diferentes processos de conquistas e colonização na América”, não há uma correspondência entre conteúdos e objetivos a ser alcançados pelos estudantes nem pelos professores.

A terceira citação da temática indígena refere-se ao subtema "Populações indígenas no sul de Mato Grosso" dentro do tema "O processo de emancipação do sul de Mato Grosso" no quarto bimestre do terceiro ano. Nele, a temática indígena é relacionada aos interesses políticos e econômicos dominantes, que, em muitos aspectos, diferem e contradizem os processos de sobrevivência dos povos indígenas em território brasileiro. O que está em jogo é a consolidação política e emancipação do sul do estado do Mato Grosso, atual estado do Mato Grosso do Sul.

Dessa perspectiva, ao somarmos temas e subtemas dos variados conteúdos a serem ministrados aos estudantes da disciplina de história à temática indígena - culturas e histórias -, é visível que ela corresponde a pouco mais de $2 \%$ dos conteúdos. As contradições estabelecidas pelo RCEM/MS prejudicam a análise e a compreensão do mínimo de conteúdo direcionado à temática indígena, fazendo com que a disciplina legitime as relações hegemônicas de poder em nossa sociedade, pois são consolidadas por verdades históricas que colocam o colonizador e o homem ocidental no centro, enquanto os povos indígenas são dispostos às margens invisíveis do processo de constituição da sociedade e suas culturas no território brasileiro.

Ao analisarmos os conteúdos, habilidades e competências da disciplina de geografia, evidenciamos aspectos de discriminação em relação à temática indígena dentro do RCEM/MS, citada em apenas dois subtemas de um total de I2I para os três anos do ensino médio, não sendo citada em nenhum tema central dos 3 I temas dispostos no Referencial. 
A primeira citação da temática indígena aparece com o item "comunidades indígenas" no quarto bimestre do primeiro ano, dentro do subtema "Conflitos no campo". Esse bimestre está estruturado em três temas centrais "Produção agropecuária”, com cinco subtemas; "Agricultura e pecuária brasileira”, com cinco subtemas; "Políticas da terra", com dois subtemas, estando o item "Comunidades indígenas" dentro do tema "Políticas da terra", no segundo subtema, intitulado "Conflitos no campo", junto a outros itens como a luta pela terra, assentamentos rurais, quilombolas e demais etnias.

A colocação de conteúdos díspares e abrangentes dentro do subtema "Conflitos no campo" pode causar confusão teórica e limitações na compreensão dos fatos históricos. Será que esses grupos estão em conflitos entre si? Por que os grupos hegemônicos ligados ao agronegócio e/ou latifúndio não estão relacionados à temática sobre conflitos no campo? O que querem dizer com o termo "demais etnias" além da perspectiva dos povos indígenas? Como será que o professor, com pouco tempo de aula para ministrar esses conteúdos - a média por bimestre é de 20 aulas de 50 minutos cada -, poderá racionalizar a melhor forma de trabalhar os conflitos no campo e todo o conteúdo do bimestre sem levar em conta contextos históricos e políticos da questão indígena no Brasil?

O item que propõe as competências e habilidades que devem ser desenvolvidas complementarmente aos conteúdos demonstra falta de preocupação em especificar e contextualizar os conteúdos ao afirmar que é necessário "caracterizar e compreender os principais problemas do espaço agrário brasileiro (política ambiental, política agrária e movimentos sociais)"; vale perguntar quais são os movimentos sociais em questão e como esses movimentos sociais podem se associar aos problemas do espaço agrário brasileiro.

Essas são questões que devem ser tratadas para demonstrar a forte dinâmica de relações de poder que tendem a favorecer os interesses da classe hegemônica por meio do RCEM/MS, apresentando-os como modernos e importantes para o desenvolvimento agrário e marginalizando as minorias indígenas como sendo ligadas unicamente aos conflitos no campo.

A segunda menção à temática indígena no RCEM/MS para a disciplina de geografia ocorre nos conteúdos referentes ao primeiro bimestre do segundo ano, intitulado "A situação dos índios e dos afrodescendentes no Brasil", dentro do tema "Etnia e cultura no mundo e no Brasil".

O termo "situação dos índios" traz uma imprecisão sobre o que deve ser estudado, deixando de oportunizar o diálogo com a diversidade de etnias indígenas de todo o território nacional, com diversidades culturais e histórias que foram e são construídas em inúmeras situações políticas. Isso entra em contradição com as competências/habilidades para esses conteúdos quando propõe "compreender a diversidade étnica cultural com base da riqueza cultural da humanidade” (MATO GROSSO DO SUL, 20I2, p. 220).

Essas citações evidenciam a dinâmica dos discursos hegemônicos em diversas configurações estereotipadas e generalizantes. A temática indígena, seus conhecimentos, histórias e culturas ficam quase ausentes dos conteúdos da disciplina de geografia e, quando são apresentados, pouco contribuem para o fortalecimento da consciência sobre a importância dos povos indígenas no processo de produção do espaço geográfico. 
Na disciplina de sociologia, a temática indígena apresenta tratamento similar ao evidenciado nas disciplinas de história e geografia. Contados 42 temas sobre vastos conhecimentos sociológicos a ser ensinados para os três anos do ensino médio, em nenhum deles aparece a temática indígena; dos 56 subtemas, em apenas um aparece a indicação "povos indígenas" ao lado de quilombolas e demais etnias não especificadas.

Há que se destacar uma maior atenção do currículo de sociologia para com o estudo das "Culturas: diversidade étnica cultural no Brasil e no Mato Grosso do Sul", que dedica todo o primeiro bimestre do segundo ano a esse campo do conhecimento, no entanto, a carga horária corresponde à metade da carga horária de história e geografia.

Apesar de a Lei n. II.684/08 (BRASIL, 2008) tornar obrigatória a inclusão das disciplinas de filosofia e sociologia no currículo do ensino médio, a carga horária definida pelas secretarias de educação a essas disciplinas é bastante reduzida. Nesse sentido, o Estado hierarquiza e engessa os saberes a ser socializados para aos estudantes, impondo barreiras para o diálogo democrático entre os muitos tipos de conhecimento humano que, destituídos das contradições e da complexidade que envolve o contexto sociocultural dos estudantes, contribuem para a alienação e a naturalização das desigualdades em nossa sociedade.

Na disciplina de filosofia não há a presença da temática indígena em qualquer dos conteúdos que fazem parte do RCEM/MS. São 20 temas e 63 subtemas sobre os mais variados conhecimentos relacionados à filosofia, sem qualquer menção aos povos indígenas, suas culturas, histórias e formas diversas de cosmologias.

O currículo para a área de conhecimento de filosofia expõe a completa sistematização e hierarquização de conhecimentos que traduzem relações históricas de poder, que evidenciam um modo de pensar único e incapaz de dialogar com outras formas de pensamentos e identidades coletivas. De acordo com Arroyo (2013, p. 122), os "currículos, seu ordenamento, as hierarquizações dos conhecimentos fazem parte das relações, experiências, interesses e tensões sociais. É ingênuo pensar que são neutros ou apenas uma transposição e um produto escolar".

Dessa perspectiva é difícil conceber a construção de uma educação pública democrática e voltada a uma política de respeito às minorias étnicas quando o currículo dispõe diferentes culturas e conhecimentos em ordenamentos hierárquicos discriminatórios que impedem o diálogo entre as diferenças na sociedade brasileira.

Os conteúdos que compreendem os povos indígenas com suas culturas e histórias na área das ciências humanas - história, geografia, sociologia e filosofia representam menos de I\% se comparados ao total geral referente a outros conteúdos nessas mesmas áreas do conhecimento incluídos no RCEM/MS.

As contradições entre o discurso pelo respeito às diversidades étnicas e a ausência de conteúdos que representam as verdadeiras culturas e histórias indígenas do Brasil no RCEM/MS demonstram o desrespeito à Lei n. II.645/08 no currículo do ensino médio do estado.

A postura do Referencial em relação à inclusão da temática indígena provoca sérios prejuízos às ações educativas no ensino dessa temática pelos professores. Esses profissionais não se veem obrigados a trazer a temática indígena para os estudantes 
por meio de um estudo analítico e crítico, haja vista que o RCEM/MS não traduz, satisfatoriamente, a participação dos povos indígenas na construção de uma sociedade justa e democrática.

\section{Propostas E EXPERIÊNCIAS QUE VALORIZAM OS POVOS INDÍGENAS NA PRODUÇÃO DO CONHECIMENTO ESCOLAR}

As análises realizadas demonstraram um excesso de estereótipos e generalizações sobre os povos indígenas nos conteúdos e discursos do RCEM/MS, em que os povos indígenas são colocados à margem da história e da cultura "oficiais" da nação, forjados por grupos e instituições representativas dos interesses e da ideologia de base eurocêntrica, que se impôs com a colonização portuguesa em território brasileiro por meio de múltiplas formas de violência que persistem até os dias atuais.

A partir das análises que demonstram que o currículo escolar do ensino médio do Mato Grosso do Sul traduz uma posição de desconhecimento e desinteresse com respeito à Lei n. II.645/08, realizamos um processo de pesquisa e estudos para trazer elementos das culturas e histórias indígenas para a sala de aula com a construção de uma proposta de trabalho que resgata materiais didáticos de apoio ao trabalho docente para além do livro didático.

Essa proposta foi construída com indicações aos materiais que discutem cultura e histórias dos povos indígenas no Brasil, com destaque para o estado do Mato Grosso do Sul, disponíveis em formato audiovisual, textual e experiências/vivências com obras artísticas. O Quadro I demonstra a classificação das obras que podem ser trabalhadas por professores e estudantes dentro e fora da escola. 


\begin{tabular}{|c|c|}
\hline \multirow{4}{*}{ 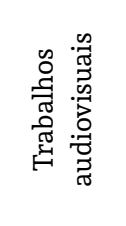 } & Videoaulas: Histórias e culturas indígenas na escola (SÃO PAULO, 2008) \\
\hline & Vídeos nas aldeias (ÍNDIOS no Brasil, 2000) \\
\hline & Associação Cultural dos Realizadores Indígenas (ASCURI, s. d.). \\
\hline & O povo brasileiro de Darcy Ribeiro (O POVO..., 1995) \\
\hline \multirow{4}{*}{ 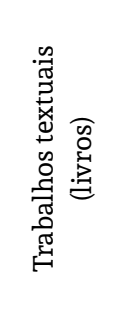 } & $\begin{array}{l}\text { A temática indígena na escola: novos subsídios para professores de } 1^{\circ} \text { e } 2^{\circ} \text { graus (SILVA; } \\
\text { GRUPIONI, 1995) }\end{array}$ \\
\hline & $\begin{array}{l}\text { Quebrando preconceitos: subsídios para o ensino das culturas e histórias dos povos indíge- } \\
\text { nas (COLLET; PALADINO; RUSSO, 2014) }\end{array}$ \\
\hline & Ensino (d)e história indígena (WITTMANN, 2015) \\
\hline & Antropologia e história dos povos indígenas em Mato Grosso do Sul (URQUIZA, 2016) \\
\hline \multirow{3}{*}{ 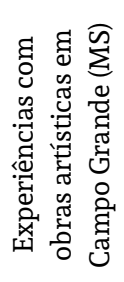 } & Museu das Culturas Dom Bosco (MCDB) \\
\hline & $\begin{array}{l}\text { Aldeia Urbana Marçal de Souza } \\
\text { Bairro Tiradentes/ Rua Terena, s/n. }\end{array}$ \\
\hline & Teatro Imaginário Maracangalha \\
\hline
\end{tabular}

Quadro I-Indicações de materiais e/ou atividades didático-pedagógicos.

Elaborado pelos autores

A maior parte dos materiais e/ou atividades didático-pedagógicos indicados são de fácil acesso a professores e estudantes e oportunizam a reflexão sobre a importância de valorizar e conhecer os povos indígenas no Brasil; são trabalhos que retratam a riqueza de culturas e histórias que não são contadas nos livros e materiais didáticos oferecidos pelo MEC e secretarias estaduais de educação nas escolas de ensino médio.

Os materiais didáticos audiovisuais propostos permitem que se trabalhem temas dos povos indígenas por meio do (re)conhecimento do diferente, como ser autônomo e detentor de especificidades culturais/comportamentais que não podem ser classificadas por meio de dualidades como inferior e/ou superior em qualquer sociedade.

Os trabalhos textuais são propostos aos professores responsáveis pelas disciplinas de história, geografia, sociologia e filosofia, possibilitando que o professor reflita sobre como as culturas e histórias dos povos indígenas no Brasil são marginalizadas e estigmatizadas dentro da educação básica. Os livros e textos trazem subsídios teóricos aos professores e estudantes debaterem o preconceito e a invisibilidade dos povos indígenas por meio de atividades questionadoras da visão etnocêntrica ainda dominante nos livros didáticos e no RCEM/MS. 


\section{CONSIDERAÇõES FINAIS}

O estado do Mato Grosso do Sul possui a segunda maior população de indígenas em todo o país, representados por diversas etnias, como guarani-kaiowá, guarani-ñandeva, terena, kadiwéu, guató, ofaié, kinikinau, atikum, kamba e chamacoco, cada qual detentora de especificidades étnicas, culturais e históricas.

A Lei n. II.645/08 ainda é uma ferramenta importante para a consolidação de uma sociedade democrática que respeite e valorize os povos indígenas no Brasil, pois, sendo vítimas mais frágeis de múltiplas violências impetradas, muitas vezes, pelo Estado, esses povos no Mato Grosso do Sul também sofrem com a invisibilidade e o preconceito em relação a suas culturas e histórias dentro das escolas.

Após mais de dez anos de promulgação da lei fica evidente que o pensamento colonial ainda é dominante nos conteúdos do currículo escolar, marginalizando e estigmatizando os povos indígenas por meio de uma óptica eurocêntrica e manipuladora dos interesses de grupos econômicos. No currículo das escolas, os povos são submetidos a conteúdos que estigmatizam suas culturas e histórias como "primitivas e ultrapassadas.

Como a instituição escolar expressa o pensamento social dominante, o currículo torna-se um gerador de controle ideológico no Mato Grosso do Sul, impossibilitando a tomada de consciência de estudantes e professores para a valorização e o diálogo com as diferenças indígenas e sua rica diversidade étnico-cultural. Quando não se trabalha a temática indígena no conteúdo do currículo ou se trabalha de forma estereotipada, como o que acontece no ensino médio do Mato Grosso do Sul, fica clara a disposição do sistema de ensino em manter um modelo autoritário e manipulador dos interesses de grupos economicamente hegemônicos e conservadores.

Entretanto, como escapar de uma estrutura educacional que serve aos interesses hegemônicos e disfarça uma postura institucional de respeito à Lei n. II.645/08? As análises realizadas apontam possibilidades de reinterpretação e questionamentos sobre os conhecimentos presentes em instrumentos de controle do trabalho didático pedagógico dos professores, como o RCEM/MS, ainda muito deficitários e pouco esclarecedores sobre a inclusão das culturas e histórias dos povos indígenas.

Os conhecimentos que por muito tempo expressavam verdades inquestionáveis dentro do currículo da educação pública hoje são constantemente discutidos por coletivos desejosos de autonomia e liberdade de pensamento. Ainda que o campo do currículo da educação básica esteja cercado de ideologias que produzem mais preconceito do que respeito e conhecimento sobre os povos indígenas no Brasil, cabe ao professor o desenvolvimento de novas formas e possibilidades para trabalhar a temática indígena nas salas de aula, com o uso do conhecimento científico, artístico e cultural construído sobre os povos indígenas disponível em vários ambientes educativos, como sites, museus, teatros e escolas.

A construção de uma sociedade democrática só é possível com a idealização de paradigmas educativos que valorizam e respeitam as diferenças étnicas no processo de formação do cidadão. Professores comprometidos com uma educação democrática devem se preparar para os desafios de uma sociedade em constante transformação. Entre esses aspectos, o cumprimento da Lei n. II.645/08 na educação básica requer 
urgência e disposição de todos os profissionais que compartilham os anseios e as inquietudes dos estudantes por uma escola cidadã e acessível às diversas formas de vivências e saberes.

\section{SOBRE OS AUTORES}

SANDERSON PEREIRA LEAL é professor de Sociologia da Secretaria Estadual de Educação de Mato Grosso do Sul na cidade de Campo Grande (SED/MS) e mestre em Educação pelo Programa Profissional em Educação da Universidade Estadual de Mato Grosso do Sul (UEMS). sandersonleal@yahoo.com.br https://orcid.org/oooo-oooI-8974-6383

WALTER GUEDES DA SILVA é professor associado do Programa de Pós-graduação Stricto Sensu - Mestrado Profissional em Educação - da Universidade Estadual de Mato Grosso do Sul (UEMS). guedes@uems.br https://orcid.org/oooo-oooI-6956-oII9

\section{REFERÊNCIAS}

ARROYO, M. G. Currículo, território em disputa. 5 ed. Petrópolis: Vozes, 2013.

ASCURI - Associação Cultural dos Realizadores Indígenas. Nossos vídeos. Disponível em: https://www. ascuri.org/videos. Acesso em: set. 2019 .

AZEVEDO, F. et al. (2006). Manifesto do Pioneiros da Educação Nova. Revista Histedbr on-line, Campinas, n. especial, p. 88-204, 2016.

BHABHA. H. O local da cultura. 3. ed. Belo Horizonte: UFMG, 2005.

BITTENCOURT, C. M. F. História das populações indígenas na escola: memórias e esquecimentos. In: PEREIRA, A. A.; MONTEIRO, A. M. (orgs.). Ensino de histórias afro-brasileiras e indígenas. Rio de Janeiro: Pallas, 20I3, p. IOI-I32. Disponível em: https://core.ac.uk/download/pdf/37520969.pdf. Acesso em: 20 fev. 2018.

BRAND, A. O impacto da perda da terra sobre a tradição kaiowá/guarani: os difíceis caminhos da palavra. I997.382f. Tese (Doutorado em História). Pontifícia Universidade Católica do Rio Grande do Sul, I997. BRAND, A. "Quando chegou esses que são nossos contrários" - a ocupação espacial e o processo de confinamento dos Kaiowá/Guarani no Mato Grosso do Sul. Multitemas, Campo Grande, n. I2, p.2I-5I, I998. Disponível em: http://www.multitemas.ucdb.br/article/view/I235/II5I. Acesso em: 3 jul 2018. BRASIL. Presidência da República. Casa Civil. Subchefia para Assuntos Jurídicos. Lei n. 9.394, de 20 de 
dezembro de I996. Estabelece as diretrizes e bases da educação nacional. Brasília: Senado Federal, 20I7. Disponível em: http://www.planalto.gov.br/ccivil_03/leis/l9394.htm. Acesso em: I4 jan. 2019.

BRASIL. Constituição da República Federativa do Brasil: texto constitucional promulgado em 5 de outubro de I988, com as alterações determinadas pelas Emendas Constitucionais de Revisão nำ I a 6/94, pelas Emendas Constitucionais nos I/92 a 9I/20I6 e pelo Decreto Legislativo ํㅡㄷ86/2008. Brasília: Senado Federal, Coordenação de Edições Técnicas, 20I6. Disponível em: https://www2.senado.leg.br/bdsf/ bitstream/handle/id/5I823I/CF88_Livro_EC9I_20I6.pdf. Acesso em: 4 jul. 2019.

BRASIL. Ministério da Educação. Parâmetros Curriculares Nacionais para o ensino médio: ciências humanas e suas tecnologias. Brasília, 2006. Disponível em: http://portal.mec.gov.br/seb/arquivos/pdf/cienciah. pdf. Acesso em: Io mai. 20I9.

BRASIL. Presidência da República. Casa Civil. Subchefia para Assuntos Jurídicos. Lei $\mathrm{n}^{\circ} \mathrm{II.645}$, de Io de março de 2008. Altera a Lei ํㅡ 9.394, de 20 de dezembro de I996, modificada pela Lei ํㅡㄴ.639, de 9 de janeiro de 2003, que estabelece as diretrizes e bases da educação nacional, para incluir no currículo oficial da rede de ensino a obrigatoriedade da temática "História e Cultura Afro-Brasileira e Indígena". Brasília: Câmara dos Deputados. Disponível em: http://www.planalto.gov.br/ccivil_03/_Ato20072010/2008/Lei/LII645.htm . Acesso em: 20 jul. 2019.

BRASIL. Presidência da República. Casa Civil. Subchefia para Assuntos Jurídicos. Lei n. II.648, de 2 de junho de 2008. Altera o art. 36 da Lei n 9.394, de 20 de dezembro de I996, que estabelece as diretrizes e bases da educação nacional, para incluir a Filosofia e a Sociologia como disciplinas obrigatórias nos currículos do ensino médio. Disponível em: http://www.planalto.gov.br/ccivil_03/_ato200720Io/2008/lei/LII684.htm. Acesso em: 20 jul. 20I9.

BRASIL. Ministério da Educação. Diretrizes Curriculares Nacionais da Educação Básica. Brasília: MEC, 20I3.

CARMO, C. R.; EDDINE, E. A. Desenvolvimento e transformação da sociedade pela educação em direitos humanos como processo permanente de conquistas. In: GUTIERREZ, J. P.; URQUIZA, A. H. A. (orgs.). Direitos humanos e cidadania: desenvolvimento pela educação em direitos humanos. Campo Grande: UFMS, 20I3, p. 223-242.

CIMI - CONSELHO INDIGENISTA MISSIONÁRIO. Relatório violência contra os povos indígenas no Brasil: dados de 20I7. I68p. Disponível em: https://cimi.org.br/wp-content/uploads/20I8/og/Relatorio-violencia-contra-povos-indigenas_20I7-Cimi.pdf. Acesso em: 30 ago. de 2019.

COLLET, C.; PALADINO, M.; RUSSO, K. Quebrando preconceitos: subsídios para o ensino das culturas e histórias dos povos indígenas. v. 3. Rio de Janeiro: Contra Capa Livraria; Laced, 20I4. (Série Traçados, v. 3). Disponível em: https://www.ufrgs.br/lhiste/quebrando-preconceitos-subsidios-para-o-ensino-das-culturas-e-historias-dos-povos-indigenas. Acesso em: set. 2019.

CURY, C. R. J. A educação básica no Brasil. Educação e Sociedade, Campinas, v. 23, n. 80, p. I68-200, 2002. Disponível em: https://www.scielo.br/pdf/es/v23n80/I2929.pdf. Acesso em: I2 jul. 2017.

FUNAI - Fundação Nacional do Índio. Índios no Brasil. Disponível em: http://www.funai.gov.br/index. php/index.php\# . Acesso em: I2 jan. 2019.

GILAVERTE, A. P. Quem são os povos indígenas para os estudantes? Reflexões sobre o currículo básico comum do estado de Minas Gerais, 09/12/20I4, I28f. Dissertação (Mestrado em Educação). Universidade Federal de São Carlos: Biblioteca Digital de Teses. Disponível em: https://repositorio.ufscar.br/handle/ ufscar/274I?show=full. Acesso em: 26 jul. 2017.

GOMES, N. L. Relações étnico-raciais, educação e descolonização dos currículos. Currículo sem fronteiras, v. I2, n. I, p. 98-I09, 20I2. Disponível em: http://www.curriculosemfronteiras.org/volı2issıarticles/ gomes.pdf. Acesso em: 4 jan. 2018.

GRAÚNA, G. Educação, literatura e direitos humanos: visões indígenas da lei II.645/o8. Educação er 
Linguagem, v. I4, n. 23/24, p. 23I-260, 20II. Disponível em: https:/www.metodista.br/revistas/revistas-metodista/index.php/EL/article/view/29I8. Acesso em: 5 fev. 2018.

GUTIERREZ, J. P. Os direitos dos povos indígenas. In: URQUIZA, A. H. A. (org.). Culturas e história dos povos indígenas em Mato Grosso do Sul. Campo Grande: UFMS, 2013, p. 28I-304.

HISTÓRIAS E CULTURAS INDÍGENAS NA ESCOLA. In: Rede do Saber. Produzido pelo Núcleo de Inclusão Educacional da Secretaria da Educação do Estado de São Paulo (videoaulas), 20I8. Disponível em: http://www.rededosaber.sp.gov.br/portais/Default.aspx?tabid=I249. Acesso em: Io set. de 2019.

IBGE - Instituto Brasileiro de Geografia e Estatística. Os indígenas no Censo Demográfico 20Io. Ministério do Planejamento, Orçamento e Gestão. Instituto Brasileiro de Geografia e Estatística. Diretoria de Pesquisas. Disponível em: https://indigenas.ibge.gov.br/images/indigenas/estudos/indigena_censo20Io.pdf. Acesso em: 29 abr. 2019.

ÍNDIOS no Brasil. Direção: Vincent Carelli. Edição: Tutu Nunes/editor. Realização: TV Escola/MEC/Vídeo nas Aldeias, Brasil (DVD), 200o. Disponível em: http://www.videonasaldeias.org.br/2009/video.php. Acesso em: 2 set. 2019.

LDB: Lei de diretrizes e bases da educação nacional. Atualizada até março de 20I7. Brasília: Senado Federal, Coordenação de Edições Técnicas, 20I7. Disponível em: http://www2.senado.leg.br/bdsf/bitstream/ handle/id/529732/lei_de_diretrizes_e_bases_Ied.pdf. Acesso em: 2 jan. 2019.

LEAL, S. P.; CALDERONI, V. A. O. A (quase) ausência de conhecimentos sobre os povos indígenas em um dos livros didáticos de sociologia da rede estadual de ensino de MS. In: CONGRESSO INTERNACIONAL DE DIREITOS HUMANOS, I2., Anais... Organização de Carla Fabiana Costa Calarge e Antonio Hilario Aguilera Urquiza. Campo Grande: UCDB, 20I5, p. 475-49I. Disponível em: https://drive.google.com/ file/d/oBıK9blGsFl_YejZTTHphZWVEQ2c/view. Acesso: 5 set. 2016.

MATO GROSSO DO SUL. Secretaria de Estado de Educação. Referencial curricular da rede estadual de ensino de Mato Grosso do Sul, Ensino Médio. Campo Grande, 2012.

MCDB - Museu das Culturas Dom Bosco. Disponível em: http://www.mcdb.org.br/. Acesso em: set. 20I9.

MIGNOLO, W. D. Desobediência epistêmica: a opção descolonial e o significado de identidade em política. Cadernos de Letras da UFF, Dossiê: Literatura, língua e identidade, n. 34, 2008, p. 287-324. Disponível em: http://www.cadernosdeletras.uff.br/joomla/images/stories/edicoes/34/traducao.pdf. Acesso em: I8 jun. 2018.

MOREIRA, A. F. B. (org.). Currículo: Questões Atuais. 6a ed. Campinas: Papirus, 2001.

O POVO brasileiro de Darcy Ribeiro. Idealização e direção: Isa Grinspum Ferraz. I995. Fundação Darci Ribeiro, TV Cultura e GNT. Disponível em: https://www.youtube.com/watch?v=rQOPdiEdX24. Acesso em: 4 set. 2019 .

SÃO PAULO (Estado). Governo do Estado de São Paulo. Secretaria da Educação. Rede do Saber. Educação Escolar Indígena. Histórias e culturas indígenas. Escola de Formação e Aperfeiçoamento dos Profissionais da Educação do Estado de São Paulo “Paulo Renato Costa Souza”. Videoaulas. 2008. Disponível em: http://www.rededosaber.sp.gov.br/portais/Default.aspx?tabid=I249. Acesso em: I set. 2019.

SILVA, A. L.; GRUPIONI, L. D. B. (orgs.). A temática indígena na escola: novos subsídios para professores de I $^{\circ} 2^{\circ}$ grau. Brasília: MEC/Mari/Unesco, I995. Disponível em: http://www.dominiopublico.gov.br/ pesquisa/DetalheObraForm.do?select_action=\&co_obra=26725. Acesso em: set. 2019.

SILVA, M. P. A temática indígena no currículo e a Lei II.645/2008: mais um desafio à realidade escolar. Revista Contexto, v. 4, n. I-2, p. III-I26, 20I3. Disponível em: https://www.fundaj.gov.br/images/stories/ epepe/III_EPEPE/a_tematica_indigena.pdf. Acesso em: 2 fev. 2018.

SILVA, M. P. A "presença” dos povos indígenas nos subsídios didáticos: leitura crítica sobre as abordagens 
das imagens e textos impressos. Mnemosine Revista, v. I, n. 2, p. 22I-243, 20Io. Disponível em: https:// bit.ly/3irRIKJ. Acesso em: I7 abr. 2015.

SOUZA, I. A Lei II.645 e a educação básica. In: URQUIZA, A. H. A. (org.). Culturas e história dos povos indígenas em Mato Grosso do Sul. Campo Grande: UFMS, 2013, p. 305-33I.

TEATRO Imaginário Maracangalha. Tekoha. Ritual de Vida e Morte do Deus Pequeno. Disponível em: http://imaginariomaracangalha.blogspot.com/p/tekoha.html. Acesso em: set. 2019.

URQUIZA, A. H. A. Antropologia e história dos povos indígenas em Mato Grosso do Sul. Campo Grande: UFMS, 2016.

URQUIZA, A. H. A.; BANDUCCI, A. Culturas e relações interétnicas, algumas aproximações conceituais. In: URQUIZA, A. H. A. (org.). Culturas e história dos povos indígenas em Mato Grosso do Sul. Campo Grande: UFMS, 2013, p. I67-2I6.

VANUCHI, P. Programa Nacional de Direitos Humanos. Secretaria Especial de Direitos Humanos. Brasília: SEDH, 2010.

WENCESLAU, M. E.; SILVA, W. G. O espaço na comunidade indígena de Dourados - identidade e alteridade. Revista Geográfica de América Central, v. 2, p. I-I2, 20II. Disponível em: http://www.redalyc.org/ pdf/45I7/45I744820538.pdf. Acesso em: I5 ago. 2018.

WITTMANN, L. T. (org.). Ensino (d)e história indígena. Belo Horizonte: Autêntica, 2015. 